\title{
Numerical Analysis of Single-Angle Steel Member Under Tension Force with Different End Deformations
}

\author{
Ahmed M. Sayed ${ }^{a, b^{*}}$ \\ ${ }^{a}$ Department of Civil Engineering, College of Engineering, Assiut University, Assiut 71511, Egypt. \\ ${ }^{b}$ Department of Civil and Environmental Engineering, College of Engineering, Majmaah University, Al-Majmaah 11952, Saudi Arabia.
}

Received 11 May 2020; Accepted 14 July 2020

\begin{abstract}
Steel members with a single-angle cross-section are widely used, but some of their behaviours under loads are not considered by design codes, necessitating related research. This study is carried out on fifty steel single-angle members focused on the stress distribution behaviour and the ultimate axial load capacities under different end deformations through 3-dimensional Finite Element (FE) simulations and comparison with previous experimental findings. FE modeling is capable of modeling steel structures with high accuracy. Based on the results, the length of the angle affects neither the shape of the stress distribution nor the ultimate load capacity of the element. The end deformations affect the stress distribution on the member angle cross-section, including the ultimate load capacity. The end deformations which restricted deformations in the two directions perpendicular to the load axis are found to be optimal, with an average increase in load capacity by a factor of 1.96 for an equal angle and 2.21 for an unequal angle compared with the capacities calculated for single angles with deformations allowed in all directions. The appearance of a compression zone on the unconnected angle leg reduces the ultimate load capacity. The current design code (ANSI/AISC-360) can be adopted to calculate the ultimate load in the case of no deformation in the $\mathrm{y}$-axis direction and no deformations in the $\mathrm{x}$ and $y$-axis directions where the mean ratios of $\mathrm{P}_{\mathrm{Num}} / \mathrm{P}_{\text {code }}$ are 1.24 and 1.34 respectively. However, the code does not agree with the end deformations of free deformations and no deformation in the $\mathrm{x}$-axis direction for either equal or unequal angles where the mean ratios of $\mathrm{P}_{\mathrm{Num}} / \mathrm{P}_{\text {code }}$ are 0.64 and 0.79 respectively, which is unsafe.
\end{abstract}

Keywords: Single Angle; End Deformations; FE Simulation; Tension Force; Stress Distribution.

\section{Introduction}

Steel tension members with a single-angle cross-section are widely used in structural applications such as trusses and lateral bracing systems. Although the loading of steel members with equal or unequal single-angle cross-sections is usually relatively simple, accurate prediction of their axial load capacities is highly difficult because of their complicated behaviours [1-3]. A single-angle section of a steel member is commonly loaded with a tension force which is decentralized in the two directions perpendicular to the principal loaded axis such that primary bending occurs about the loaded axis [4-6]. Because the cross-section consists of a single angle, during fixation, only one leg is connected to the steel loading plate, and the other is left unfixed. This causes problems in the presence of a decentralized load in addition to the end deformations of the element in relation to the deformation. Therefore, when using a steel element with a single-angle cross-section with permissible deformations at one end of the steel element in one direction or two directions perpendicular to the direction of the loading axis, some deformations occur over the

\footnotetext{
* Corresponding author: a.sayed@mu.edu.sa
} 
entire length of the steel element. These problems may affect the distribution of stresses on the cross-section of the element and thus cause a decrease in the maximum capacitance of the steel element to be obtained.

The existence of this unconnected leg, whether short or long, in steel angles or channels significantly affects the stress distribution, ultimate load capacity, and mechanical response of steel structures [7,8]. Because of the behaviour of such sections, numerical [9-11] and experimental studies [12-14] in this field have intensified over the past two decades. Additionally, some research has been performed on the influence of the connection by using steel angles [15] and also, some research has been performed on the influence of the bending moment [16, 17]. A few studies have proved that the behaviour of a single-angle steel member under a tension force experiences a nonlinear stress distribution [18, 19], as shown in Figure 1. However, this research has not considered different end deformations (the directions in which displacement is allowed and restricted) or the compression zone occurring in the unconnected angle leg. Because of the limited experimental information currently available, in addition to previously unconsidered variables, is necessary to further examine these systems to understand the behaviour of steel members with a singleangle cross-section, expand their use, and improve existing design codes.

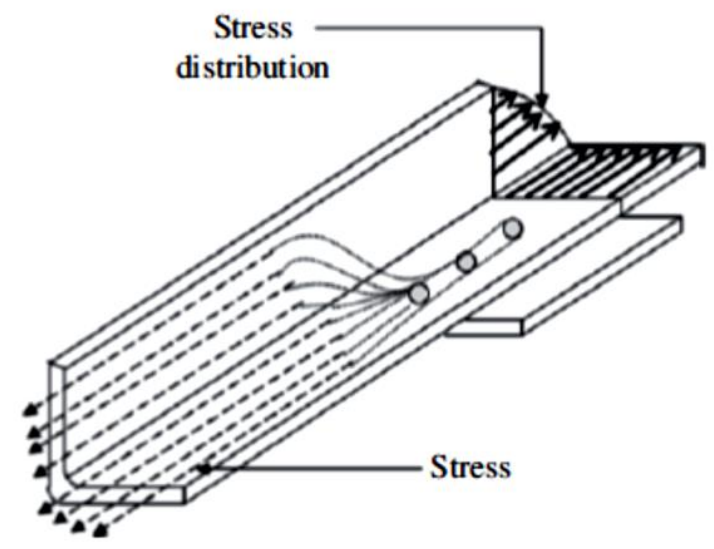

(a) Unconnected lag effect in angle tension members [18]

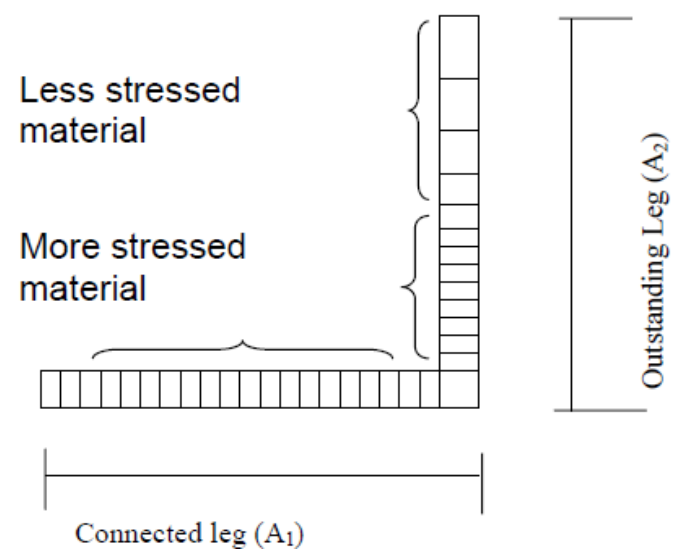

(b) Non-uniform stress distribution in angles [19]

Figure 1. Distribution of stresses on a steel single-angle section

The present study aimed to investigate the behaviour of equal and unequal single-angle steel members using finite element (FE) simulations and analysis, which are currently widely used to analyze steel structural elements and have been shown to give highly accurate results [20-22]. The single angles are connected through one leg by welding connections under different end deformations, where the deformation is controlled in the two directions perpendicular to the load axis. Several parameters are examined, including angle dimensions, cross-sectional area, equal and unequal angle dimensions, steel element length, and end deformations.

When using existing design codes [23-25], it does not take into account the effect of deformations resulting in the steel element due to some deformations permitted on one of the ends of the steel element. Therefore, it is necessary to make a study that takes into account the deformations at the edge of the steel element and the amount of its influence in the form of stress distribution as well as the maximum capacity of the steel element. Numerical analysis is performed on 50 samples of steel elements of an equal or unequal single-angle section. A number of them will be used to verify the use of the numerical analysis process and its accuracy. The rest of the samples will be used to study the distribution of stresses and also to verify the accuracy of the use of the current design codes in predicting the maximum load capacity of the steel element with a single-angle cross-section.

\section{Ultimate Tension Load Capacity by Current Code Equations}

The design tensile strength defined by ANSI/AISC-360 [23], $\phi P_{\mathrm{n}}$, of tension members is obtained according to the tensile rupture in the net section:

$P_{n}=f_{u} \cdot A_{e}$

Where; $P_{\mathrm{n}}$ is the nominal section tension axial capacity $(\mathrm{kN}), f_{\mathrm{u}}$ is the steel ultimate strength (MPa), and $A_{\mathrm{e}}$ is the effective net section area of the member $\left(\mathrm{mm}^{2}\right)$, which is determined by:

$A_{e}=A_{n} \cdot U$

Where; $A_{\mathrm{n}}$ is the net cross-sectional area $\left(\mathrm{mm}^{2}\right)$, and $U$ is the shear lag factor. In single-angle or channel sections which are connected with one leg, the shear lag effect is accounted for by a reduction in the net section area; the 
reduced net section area is obtained by multiplying by the coefficient $U$. If the tension force is applied to some but not all of the cross-section steel elements by longitudinal welding or fasteners, $U$ is given by:

$U=1-\frac{\bar{X}}{l} \leq 0.9$

Where; $l$ is the length of the welded connection $(\mathrm{mm})$ and $\bar{X}$ is the eccentricity of the connection (mm). If the tension force is applied directly to all the cross-section steel element by welding or fasteners, then $U=1.0$.

To obtain tensile strength values for a safe design, the load value $P_{\mathrm{n}}$ is multiplied by a safety factor $\phi$, which is equal to 0.75 according to ANSI/AISC-360 [23].

The model offered by Eurocode-3: 1-1 [24] to calculate the design tension axial force of a steel member is given by:

$$
P_{d}=\frac{0.9 A_{n} \cdot f_{u}}{\gamma_{m 2}}
$$

To obtain safely designed tensile strength values, the partial safety factor $\gamma_{m 2}$ must be introduced with a value of 1.25 according to Eurocode-3: 1-1 [24].

In Australian code AS 4100 [25], the nominal steel section axial load capacity for the tension of steel member is given by:

$$
P_{n}=0.85 k_{t} \cdot A_{n} \cdot f_{u}
$$

Where; 0.85 is an additional safety factor and $k_{\mathrm{t}}$ is a factor to account for the distribution of forces and eccentric loading, which is set to 0.85 according to Australian code AS-4100 [25]. A member subject to a design axial tension force $P_{\mathrm{d}}$ shall satisfy $\phi P_{\mathrm{n}}$, where $\phi$ is the capacity factor and is equal to 0.9 according to AS-4100 [25].

Of all current codes, none consider the effect of the end deformations of the steel element, and none state acceptable parameters regarding the compression zone occurring in the free-angle leg due to decentralisation of the applied load. In this study, numerical analysis is conducted on steel members with cross-sections of equal and unequal single angles and different end deformations to verify the accuracy of the equations in current design codes. The design code ANSI/AISC-360 [23] is selected to compare with the numerical analysis since it has the highest safety coefficient of the mentioned design codes, and the model parameters are the same as those described above.

\section{ANSYS Finite Element Model Study}

\subsection{Steel Modelling and Characteristics}

The steel members with single-angle cross-sections are simulated using SOLID186 element ANSYS 15 [26] with 20 nodes and 3 degrees of freedom. This element is capable of simulating various properties, the most important of which are plasticity, stiffening of stress, large deflection, larger capabilities of strain, and capability to simulate elasticplastic deformations. To model steel structural elements, the stress-strain engineering relationship must be used. The engineering stress-strain relationship and elastic modulus of the steel elements, which are measured experimentally by tension tests, are acquired from a previously published work [7]. The average engineering stress-strain relationship of the tension test results [7] is applied to FE modeling, as shown in Table 1, with elastic modulus is set to $203 \mathrm{GPa}$, and a Poisson's ratio of 0.3 is applied [20-22]. The model is divided into small elements with $l \times w \times h$ of $10 \times 5 \times 5 \mathrm{~mm}$ as a maximum size.

Table 1. Average engineering stress-strain [7] relationship that is used in the FE simulation

\begin{tabular}{ccccccccc}
\hline Stress (MPa) & 264 & 268 & 279 & 335 & 381 & 401 & 411 & 418 \\
Corresponding Strain & 0.0013 & 0.0087 & 0.0150 & 0.0400 & 0.0997 & 0.1499 & 0.1998 & 0.2496 \\
\hline
\end{tabular}

\subsection{Numerical Specimen Studies}

Numerical FE analysis is carried out on fifty steel single-angle members with variable geometrical dimensions and different end deformations, where the deformations are controlled in the two directions perpendicular to the load axis. Two specimens of unequal single angles with dimensions of $125 \times 75 \times 10$ (denoting long leg length $\times$ short leg length $\times$ thickness in millimeters) are set as control specimens to verify the FE results with the experimental results in a previously published work [7], as shown in Figure 2. For the control specimens, the end deformations are set such that no deformations occurred at the fixed end in any direction, and at the loading end, no deformations occurred in the directions of the axes perpendicular or parallel to the direction of the unconnected angle leg, as shown in Figure 2. 
Twenty-eight specimens are equal single angles and twenty specimens are unequal single angles. These samples are divided into four main groups, each consisting of twelve specimens depending on the end deformations: free deformations in the $\mathrm{x}-, \mathrm{y}-$, and $\mathrm{z}$-axis directions; no deformations in the direction of the axis perpendicular to the applied load axis or of the unconnected angle leg ( $\mathrm{x}$-axis); no deformations in the direction of the axis perpendicular to the applied load axis or parallel to the direction of the unconnected angle leg (y-axis); and no deformations in the direction of either the $\mathrm{x}$ - and $\mathrm{y}$-axis. All the samples are subjected to an axial tension force in the direction of the longitudinal axis of the angle elements. Rigid steel plates with cross-sections greater than that of the angles are used to fix the angles. The steel angles and plates are attached by welding connections with a length equal to $200 \mathrm{~mm}$, as shown in Figure 2. The angles are connected to the loading plates by a direct bond between the two with a connected width equal to the welding thickness.

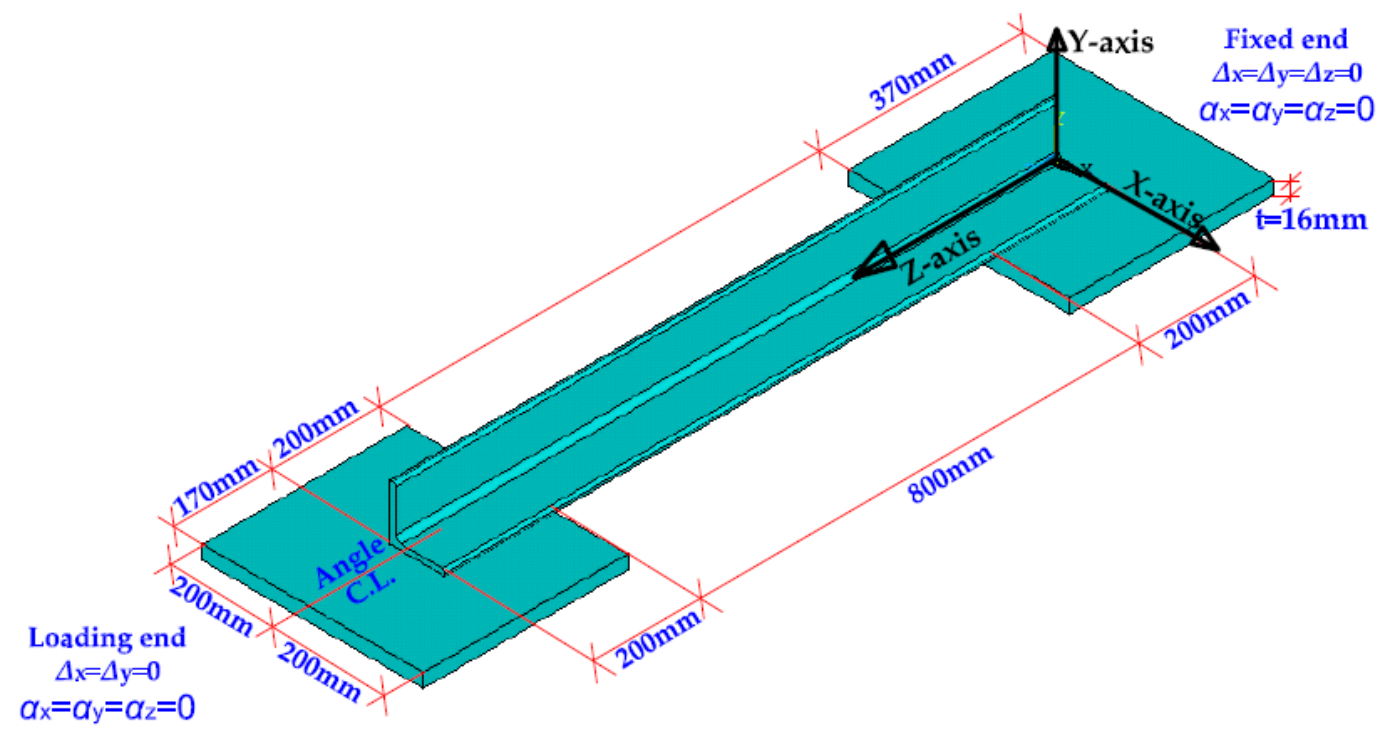

Figure 2. Modelling details according to previously published work [7]

\section{Verification of FE Results with Experimental Results}

To analyze the validity and reliability of FE modelling, verification is performed by a comparison with the previously reported experimental results [7]. The experiments are performed by applying a tension load to two steel members with an unequal single angle cross-section $(125 \times 75 \times 10)$ connected by one leg. Under the same end deformations and dimensions, one is connected by the long-angle leg of $125 \mathrm{~mm}$, while the other is connected by the short-angle leg of $75 \mathrm{~mm}$, as shown in Figure 2. The load-elongation relationships for the specimens employed in the FE analysis and corresponding experimental results are shown in Figure 3. A comparison of the two sets of results indicates an excellent agreement.

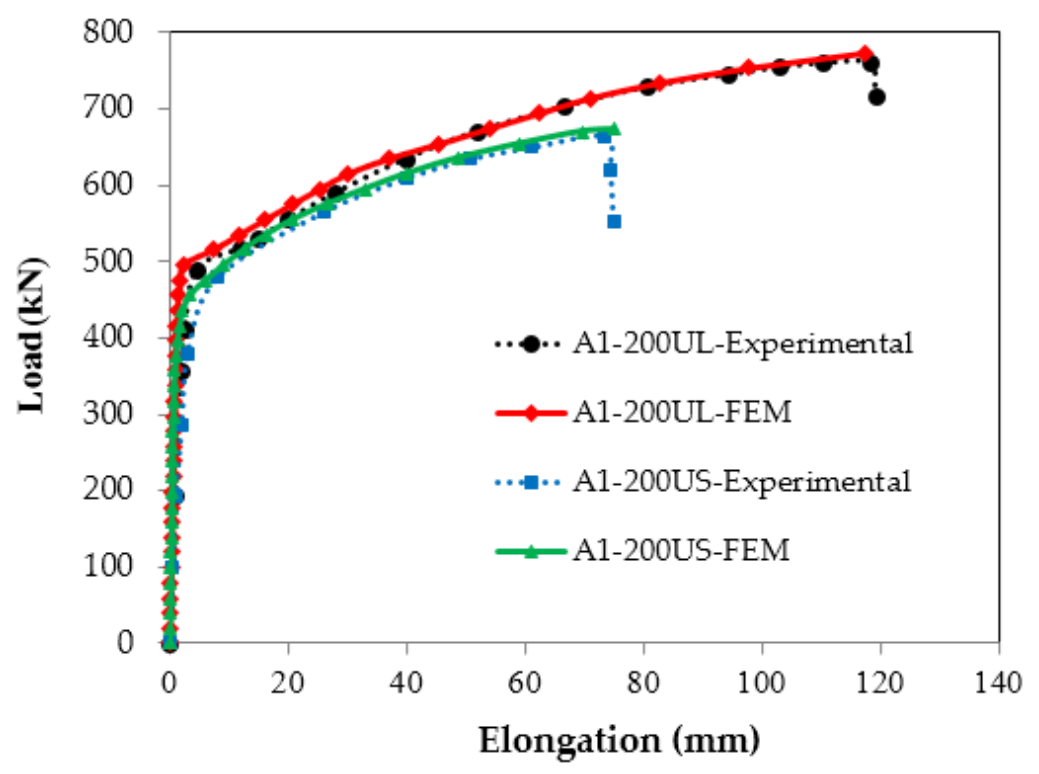

Figure 3. Comparing load-elongation relationships between experimental [7] and FE results 
Table 2 shows the experimental and FE-modelled load capacities and final elongations, as well as their ratios. The mean ratio of the load capacities $P_{\mathrm{FEM}} / P_{\mathrm{Exp}}$ is 1.015 , and that of the final elongation $\Delta_{\mathrm{FEM}} / \Delta_{\mathrm{Exp}}$ is 1.006 . These values illustrate that FE analysis has a high accuracy for the simulation of steel elements. From Figure 4, which shows the deformation shape for the experimental specimen and FE model, excellent agreement is also observed between these two sets of data.

Table 2. Comparison of experimental and FE results

\begin{tabular}{cccccccc}
\hline $\begin{array}{c}\text { Angle } \\
\text { specimen }\end{array}$ & $\begin{array}{c}\text { Specimen } \\
\text { name [7] }\end{array}$ & $\begin{array}{c}\text { Connected } \\
\mathbf{l e g}(\mathbf{m m})\end{array}$ & $\begin{array}{c}\text { Ultimate load } \\
\boldsymbol{P}_{\text {FEM }}(\mathbf{k N})\end{array}$ & $\begin{array}{c}\text { Final elongation } \\
\boldsymbol{\Delta}_{\text {FEM }}(\mathbf{m m})\end{array}$ & $\begin{array}{c}\text { Experimental } \\
\text { [7] } \boldsymbol{P}_{\text {Exp }}(\mathbf{k N})\end{array}$ & $\begin{array}{c}\boldsymbol{P}_{\text {FEM }} / \boldsymbol{P}_{\text {Exp }} \\
\text { [7] } \boldsymbol{\Delta}_{\text {Exp }}(\mathbf{m m})\end{array}$ & $\begin{array}{c}\text { Experimental } \\
\boldsymbol{\Delta}_{\text {FEM }} / \boldsymbol{\Delta}_{\text {Exp }}\end{array}$ \\
\hline $125 \times 75 \times 10$ & A1-200UL & 125 & 773 & 117.46 & 760 & 1.017 \\
$125 \times 75 \times 10$ & A1-200US & 75 & 673 & 75.28 & 665 & 1.012 \\
\hline
\end{tabular}

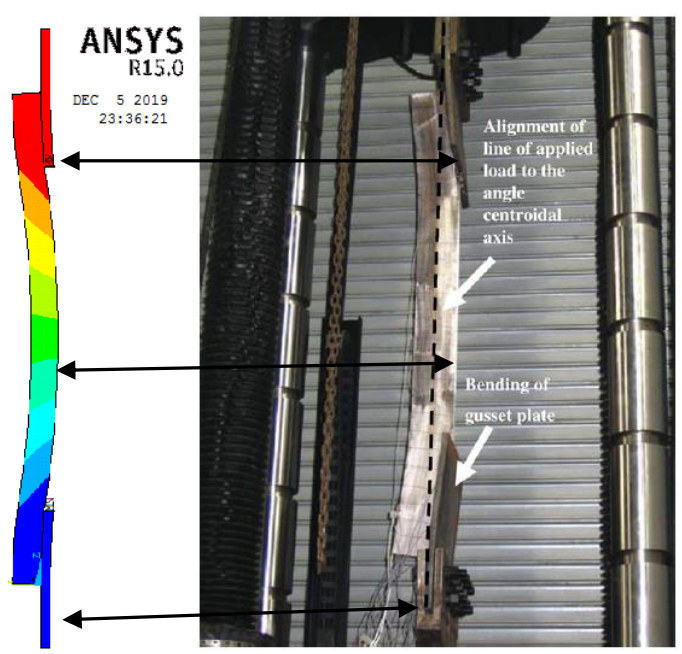

Figure 4. Deformation shapes of specimens obtained from experimental tests [7] and FE modelling

\section{Numerical Results and Discussion}

Using the considered parameters, it is possible to predict the ultimate load capacity of steel members with a singleangle cross-section by FE analysis. Consequently, the ultimate load capacity and tension stress distributions of a steel single angle are affected by different end deformation deformations. Table 3 lists the FE-calculated ultimate load capacities and average tension stresses for steel members with a single-angle cross-section under different end deformations. The average tensile stress is determined by calculating the total tensile stress area and dividing it by the length of the tensile stress distribution.

Table 3. Summary of steel angle specimens with different end deformations based on FE results

\begin{tabular}{|c|c|c|c|c|c|c|c|c|c|}
\hline \multirow[b]{2}{*}{$\begin{array}{c}\text { Angle } \\
\text { specimen }\end{array}$} & \multirow{2}{*}{$\begin{array}{c}\text { Angle } \\
\text { length } \\
(\mathrm{mm})\end{array}$} & \multicolumn{2}{|c|}{$\begin{array}{c}\text { Free deformations in } x \text {-, } \\
y \text {-, and } z \text {-axes }\end{array}$} & \multicolumn{2}{|c|}{ No deformation in $x$-axis } & \multicolumn{2}{|c|}{ No deformation in $y$-axis } & \multicolumn{2}{|c|}{$\begin{array}{l}\text { No deformations in } x \text { - } \\
\text { and } y \text {-axis }\end{array}$} \\
\hline & & $\begin{array}{l}\text { Ultimate } \\
\operatorname{load}(\mathbf{k N})\end{array}$ & $\begin{array}{c}\text { Average } \\
\text { stress } \\
\text { (MPa) }\end{array}$ & $\begin{array}{r}\text { Ultimate } \\
\operatorname{load}(k N)\end{array}$ & $\begin{array}{c}\text { Average } \\
\text { stress } \\
\text { (MPa) }\end{array}$ & $\begin{array}{l}\text { Ultimate } \\
\operatorname{load}(k N)\end{array}$ & $\begin{array}{c}\text { Average } \\
\text { stress } \\
\text { (MPa) }\end{array}$ & $\begin{array}{l}\text { Ultimate } \\
\operatorname{load}(\mathbf{k N})\end{array}$ & $\begin{array}{c}\text { Average } \\
\text { stress } \\
\text { (MPa) }\end{array}$ \\
\hline \multirow[t]{3}{*}{$50 \times 50 \times 5$} & 1000 & 92.38 & 384.76 & 117.53 & 413.55 & 167.90 & 348.42 & 179.14 & 374.91 \\
\hline & 1500 & 92.38 & 384.76 & 117.53 & 413.55 & 167.49 & 348.21 & 177.23 & 372.85 \\
\hline & 2000 & 92.38 & 384.76 & 117.53 & 413.55 & 167.89 & 348.42 & 179.14 & 374.91 \\
\hline \multirow[t]{3}{*}{$75 \times 75 \times 7$} & 1000 & 193.43 & 386.94 & 240.87 & 416.12 & 349.08 & 346.63 & 378.64 & 375.73 \\
\hline & 1500 & 193.43 & 386.94 & 240.87 & 416.12 & 349.08 & 346.63 & 378.64 & 375.73 \\
\hline & 2000 & 193.43 & 386.94 & 240.87 & 416.12 & 349.08 & 346.63 & 378.64 & 375.73 \\
\hline $100 \times 100 \times 10$ & 1000 & 356.92 & 375.27 & 436.23 & 408.63 & 648.47 & 338.54 & 709.00 & 369.87 \\
\hline $60 \times 40 \times 5$ & 1000 & 84.95 & 341.65 & 104.23 & 410.89 & 172.28 & 361.94 & 186.25 & 387.68 \\
\hline \multirow[t]{3}{*}{$90 \times 60 \times 6$} & 1000 & 153.22 & 343.23 & 189.16 & 413.74 & 315.26 & 361.78 & 342.68 & 393.22 \\
\hline & 1500 & 153.22 & 343.23 & 189.16 & 413.74 & 315.26 & 361.78 & 342.68 & 393.22 \\
\hline & 2000 & 153.22 & 343.23 & 189.16 & 413.74 & 315.26 & 361.78 & 342.68 & 393.22 \\
\hline $120 \times 80 \times 10$ & 1000 & 337.09 & 338.84 & 409.27 & 406.09 & 696.83 & 366.14 & 743.02 & 390.56 \\
\hline
\end{tabular}




\subsection{Effect of Angle Length}

From the numerical analysis, the length of the angle does not have an effect on the stress distribution or total force on the angle section. This is because the direction of the load is parallel to the angle center line, and the bending moment is the result of multiplying the applied load by decentralized of the angle regardless of the length of the angle itself. For lengths of 1000, 1500, and $2000 \mathrm{~mm}$, no significant differences are observed, even with different end deformations for each angle, as shown for the equal angle $50 \times 50 \times 5$ in Figure (5-a). Numerical analysis of another equal angle $75 \times 75 \times 7$ (Figure (5-b)) and an unequal angle $90 \times 60 \times 6$ (Figure 6) indicated the same trend. This is fully consistent with all design codes as they do not consider the effect of angle length in calculating the design force or stress distribution in the section.

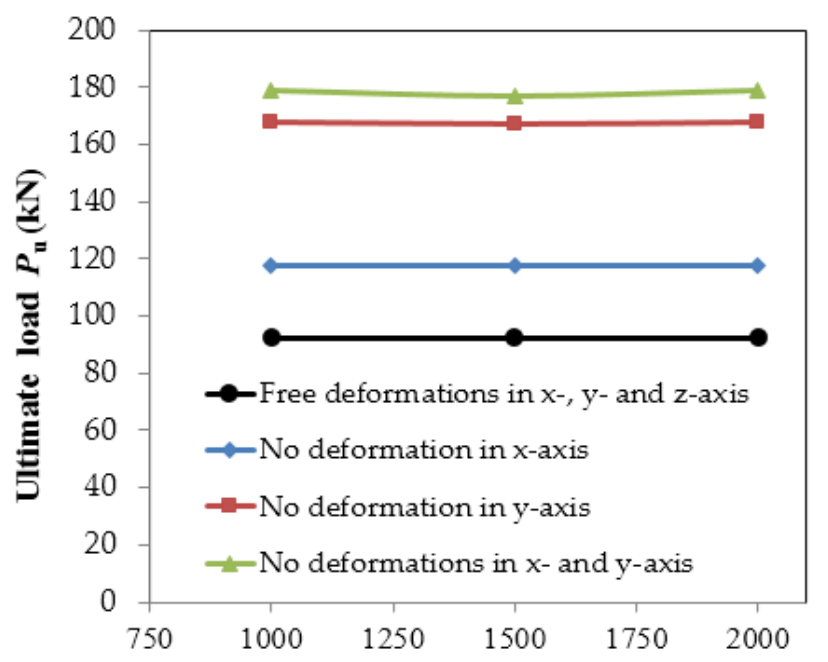

Angle length (mm)

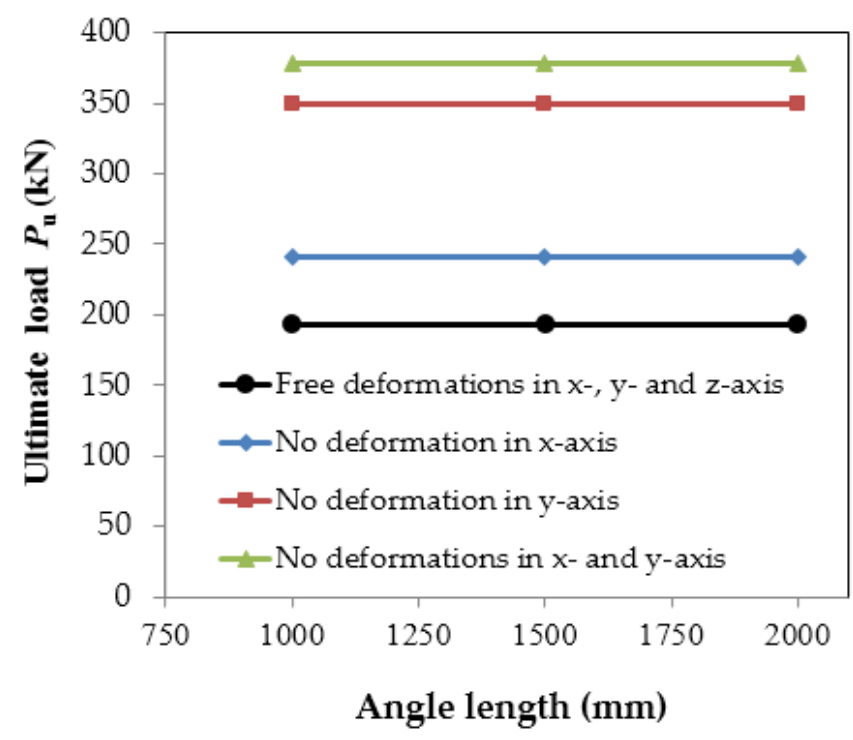

(b) Equal angle $75 \times 75 \times 7$

(a) Equal angle $50 \times 50 \times 5$

Figure 5. Relationship between angle length and ultimate stress of equal angles with different end deformations

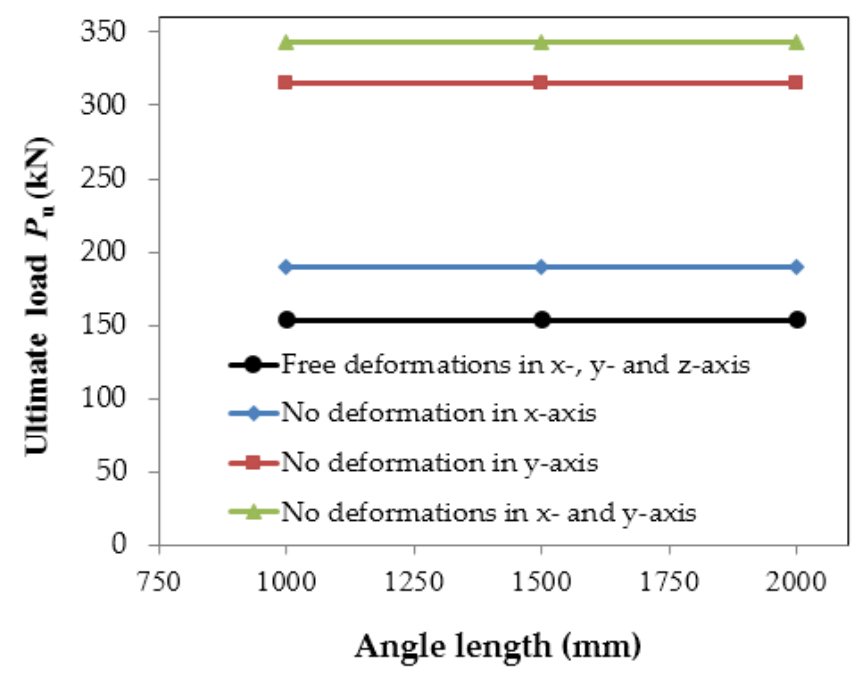

Figure 6. Relationship between angle length and ultimate stress of unequal angle $90 \times 60 \times 6$ with different end deformations

\subsection{Influence of End Deformations}

The effect of the end deformations is essential, especially in asymmetric sections such as single-angle sections. In general, all end deformations yielded an irregular stress distribution along the element cross-section, as shown in Figures 7 and 8 for equal and unequal angles, respectively. However, this distribution varied according to the end deformations. It is found that when the end is free deformations in all directions, the amount of decentralization around the two axes that are perpendicular to the loading axis generates significant bending moments around these two axes, causing compression stress at the end of the angle legs as shown in Figure (7-a) of the equal angle and Figure (8a) of the unequal angle. When preventing the deformation in the direction of the axis of the angle leg connected to the loading plate, the generate moment is only one bending moment around this axis and causes compression stress at the 
end of the disconnected angle leg as in Figure (7-b) of the equal angle and Figure (8-b) of the unequal angle. Moreover, when preventing deformation in the direction of the axis of the angle man not connected to the loading plate. As a result, it causes the presence of a bending moment around the two axes that are perpendicular to the loading axis, and this results in a decrease in the tension stress distribution at the ends of the angle legs, but does not reach the presence of compression stress as shown in Figure (7-c) for the equal angle and Figure (8-c) for the unequal angle. When preventing deformation in the two directions that are perpendicular to the loading axis, a small bending moment around the axis is produced in the direction of the angle leg connected to the loading plate only. It causes a decrease in the tension stress distribution at the end of disconnected angle leg, as is evident in Figure (7-d) for the equal angle and Figure (8-d) for the unequal angle.

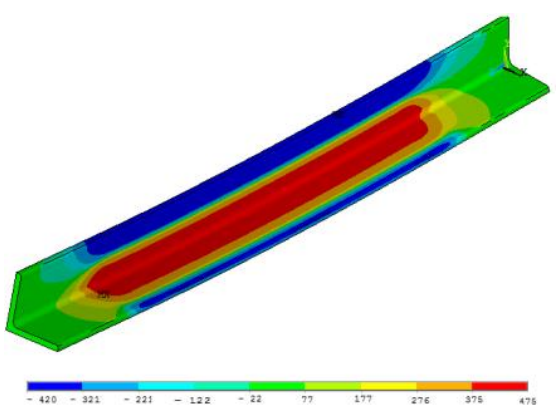

(a) With free deformations in $x-, y$-, and $z$-axes

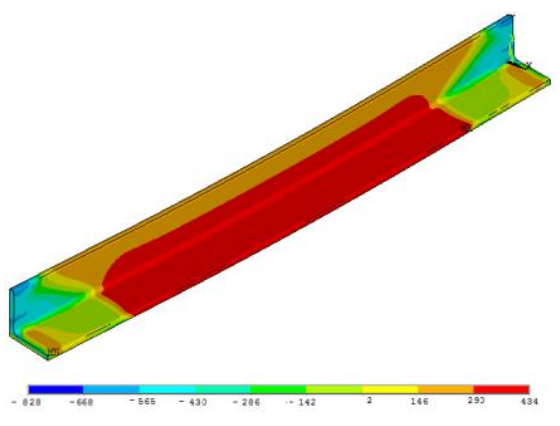

(c) With no deformation in $y$-axis

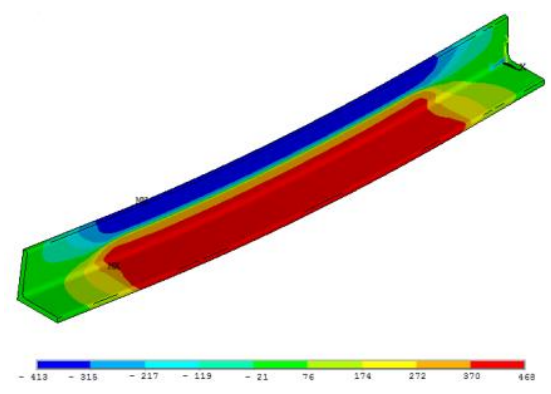

(b) With no deformation in $x$-axis

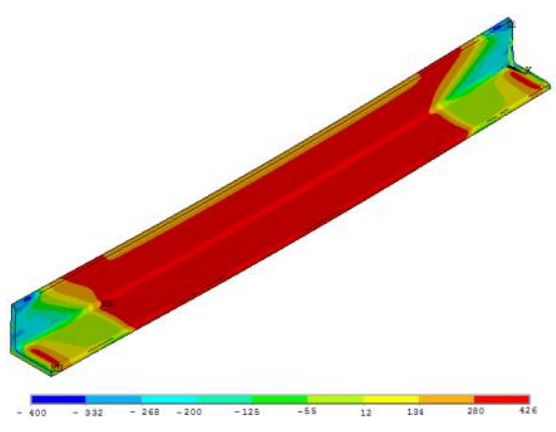

(d) With no deformations in $x$ - and $y$-axis

Figure 7. Effect of end deformations on stress distribution of equal angle $100 \times 100 \times 10$

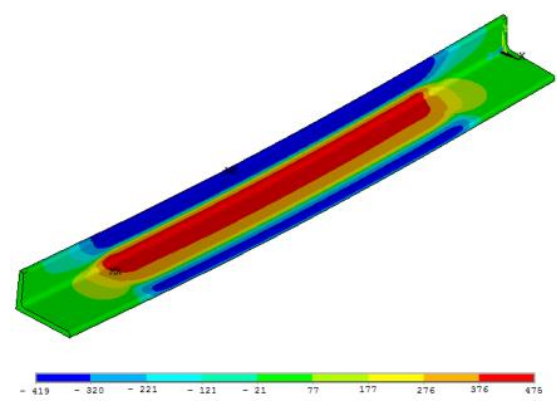

(a) With free deformations in $x$-, $y$-, and $z$-axes

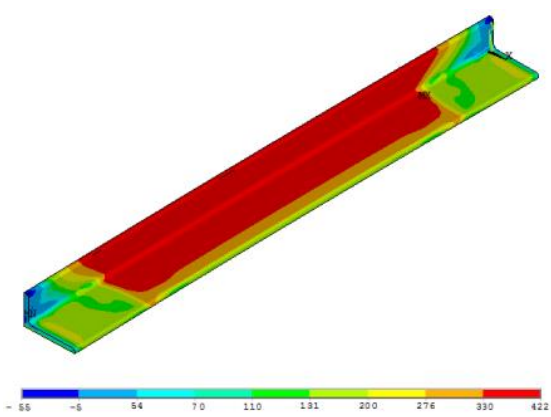

(c) With no deformation in $y$-axis

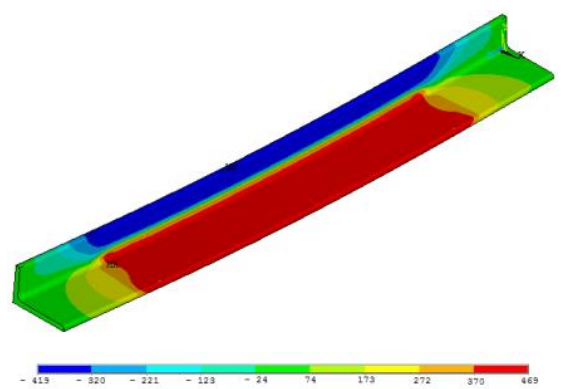

(b) With no deformation in $x$-axis

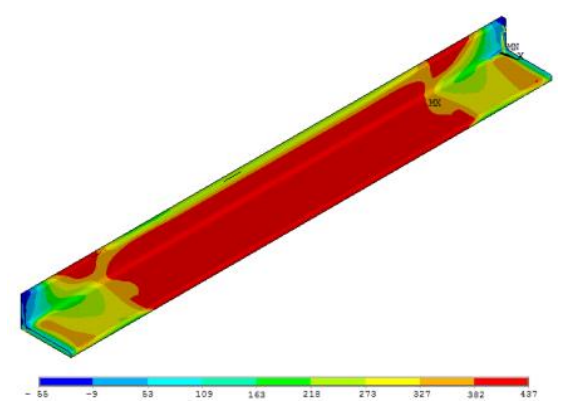

(d) With no deformations in $x$ - and $y$-axis

Figure 8. Effect of end deformations on stress distribution of unequal angle $120 \times 80 \times 10$ 


\section{- End Deformations with Free Deformations in the $x$-, $y$-, and z-Axis Directions}

For the elements with free deformations in the $\mathrm{x}-, \mathrm{y}-$, and $\mathrm{z}$-axis directions, the end moves in both directions perpendicular to the load axis, as shown in Figure 9. The connected and unconnected angle legs have irregularly distributed stress with the maximum tensile stress located at the corner of the angle. Both equal angle legs experience tensile and compression stress, where the tensile zones are measured as $84.52 \%$ and $58.23 \%$ of the connected and unconnected leg lengths, respectively. For the unequal angle, both legs also experience tensile and compression stress, where the tensile zones are measured as $87.43 \%$ and $49.63 \%$ for the connected and unconnected legs, respectively, as shown in Figure 10. The occurrence of a compression zone in the legs of the angle significantly affects the maximum capacity of the steel element. This deficiency in the distribution of tensile stress is caused by the decentralization of the angle in the two directions, which are perpendicular to the direction of the loading axis.

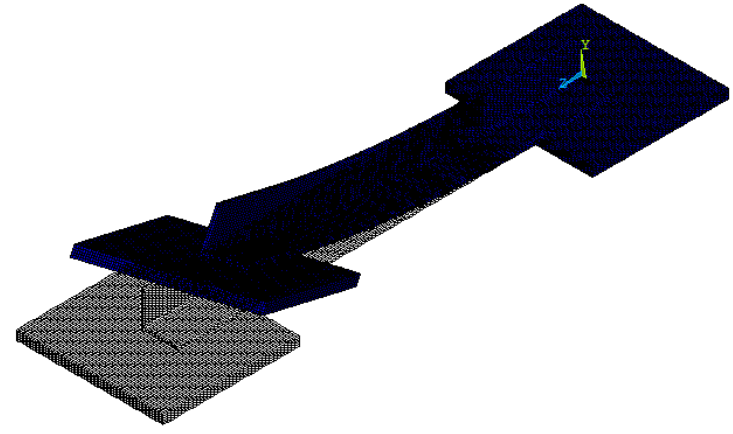

(a) Three-dimensional view

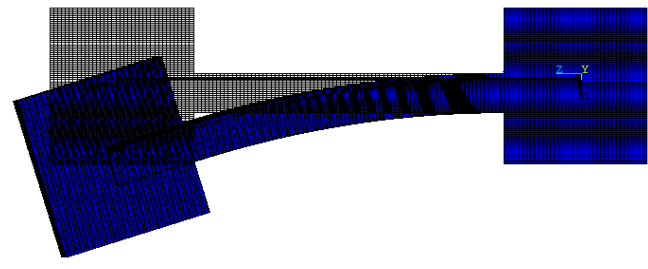

(b) Perpendicular to the unconnected leg

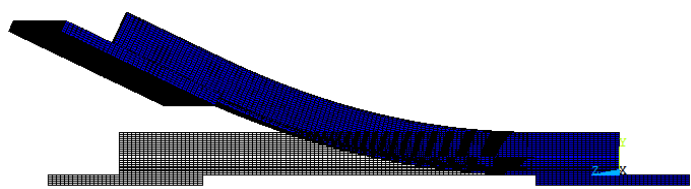

(c) Parallel to the unconnected leg

Figure 9. Deformation shape of steel angle member with free deformations in the $x-, y-$, and z-axis directions

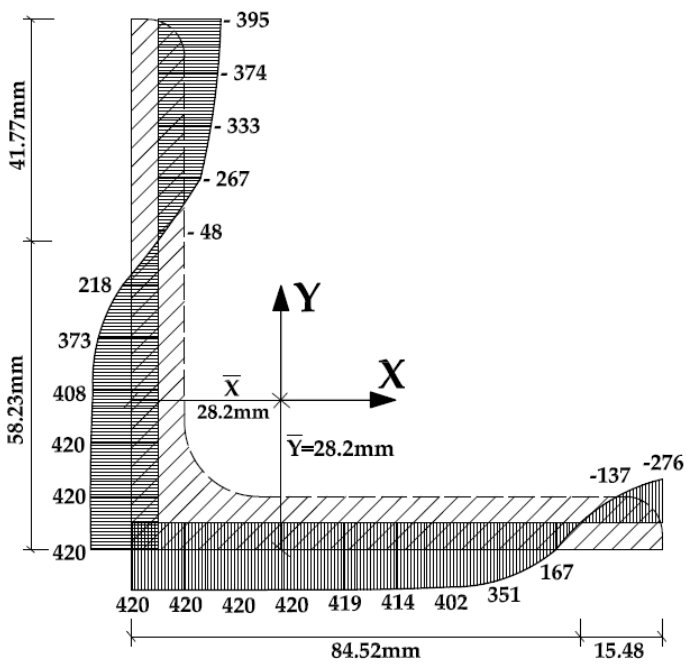

(a) Equal angle $100 \times 100 \times 10$

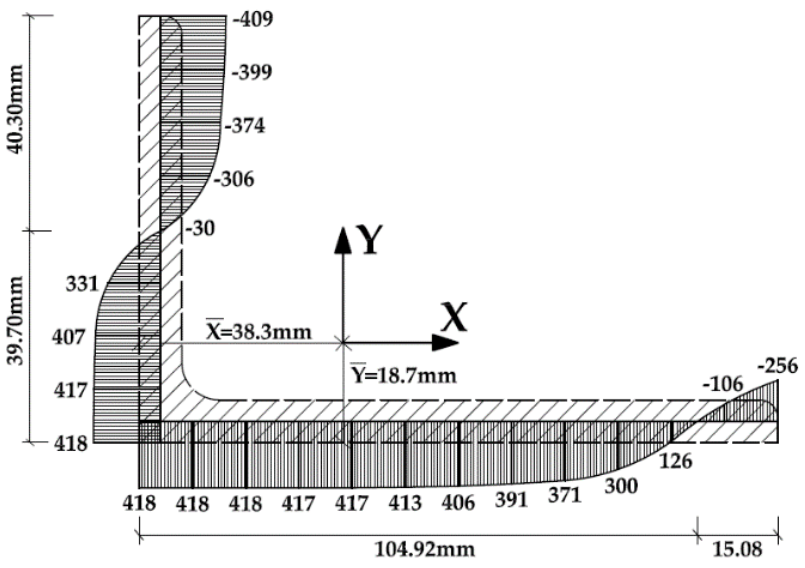

(b) Unequal angle $120 \times 80 \times 10$

Figure 10. Ultimate stress distributions for angles with free deformations in the $x-, y-$, and $z$-axis directions

\section{- End Deformations with No Deformation in the $x$-Axis Direction}

If no deformations are allowed in the direction perpendicular to the applied load axis or perpendicular to the direction of the unconnected angle leg (x-axis), as shown in Figure 11, the section properties are greatly improved. In this situation, the stress distributions are now regular, and only the unconnected leg experiences tensile and compression stresses. For equal and unequal angles, the tensile zone in the unconnected leg decreases in height, reaching $51.72 \%$ and $37.66 \%$, respectively, of the full height of the unconnected angle leg, as shown in Figure 12. This deficiency in the distribution of tensile stress is caused by the presence of the bending moment generated in the direction of the disconnected angle leg. 


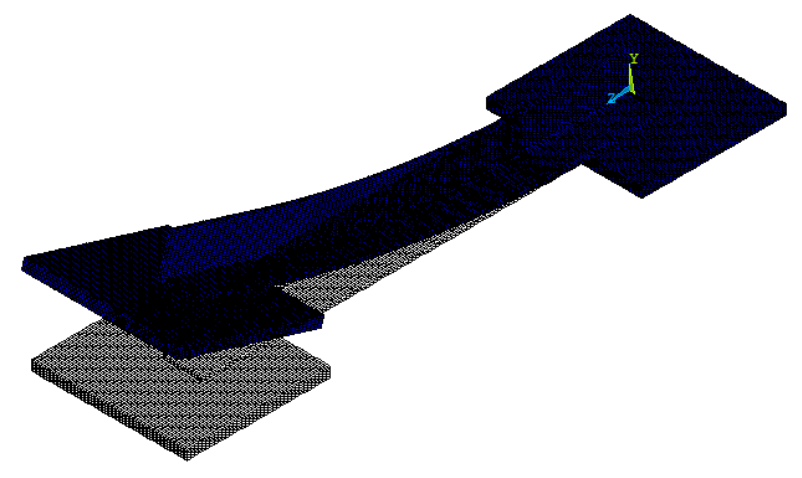

(a) Three-dimensional view

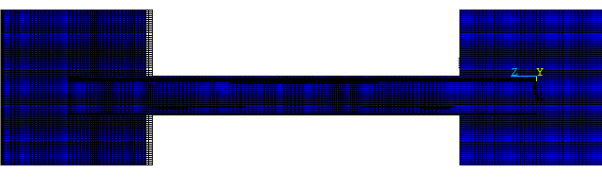

(b) Perpendicular to the unconnected leg

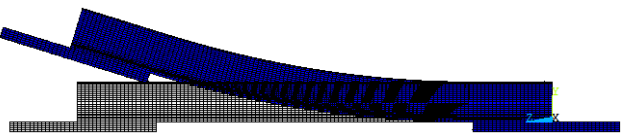

(b) Parallel to the unconnected leg

Figure 11. Deformation shape of steel angle member with no deformation in the $\mathrm{x}$-axis direction

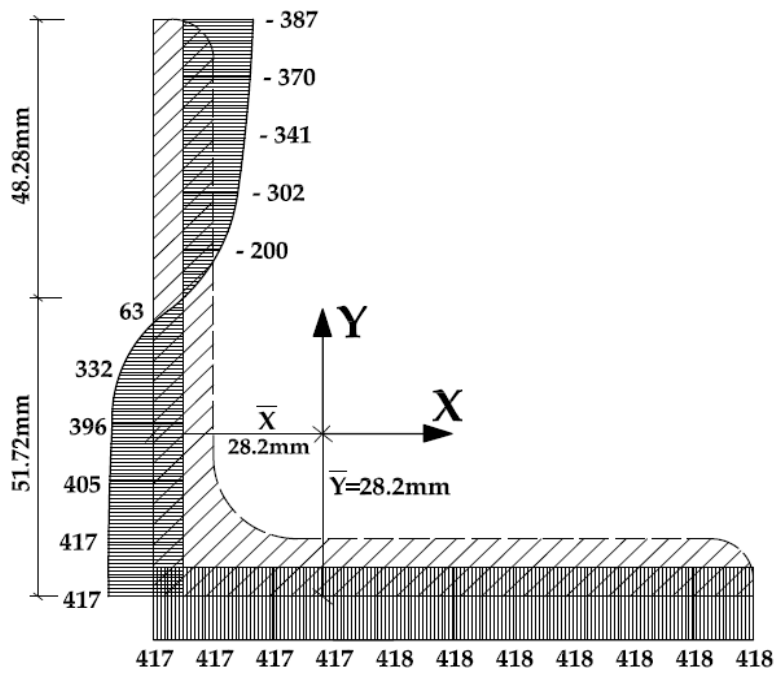

(a) Equal angle $100 \times 100 \times 10$

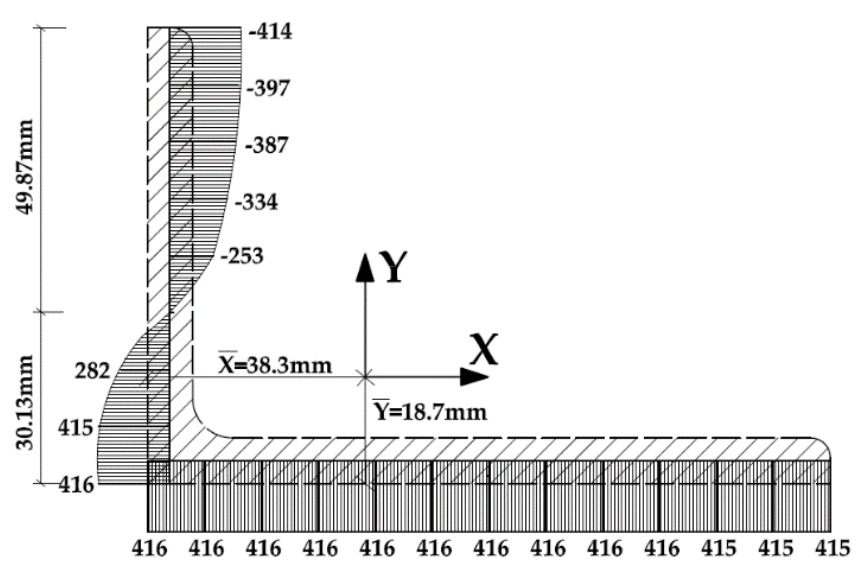

(b) Unequal angle $120 \times 80 \times 10$

Figure 12. Ultimate stress distributions for angles with no deformation in the $x$-axis direction

\section{- End Deformations with No Deformation in the y-Axis Direction}

If no deformation is allowed in the direction perpendicular to the applied load axis or parallel to the direction of the unconnected angle leg (y-axis), as shown in Figure 13, the section is improved in terms of stress. Only tensile stress is observed in the unconnected leg, and no compression stress is measured. However, for the connected angle leg, the stress is irregularly distributed, and the maximum value is located at the end of the equal angle leg and at the corner of the unequal angle, as shown in Figure 14. Non-uniform distribution of tensile stress is caused by the presence of bending moments around the two axes, which is perpendicular to the loading axis due to the presence of decentralization.

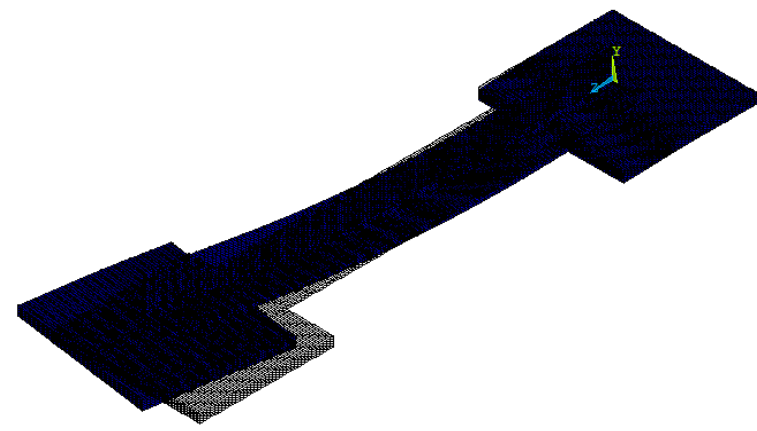

(a) Three-dimensional view

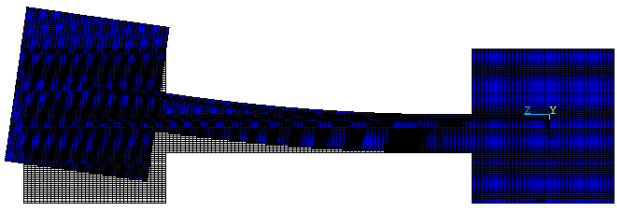

(b) Perpendicular to the unconnected leg

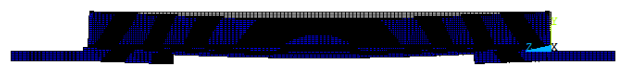

(b) Parallel to the unconnected leg

Figure 13. Deformation shape of steel angle member with no deformation in the $y$-axis direction 


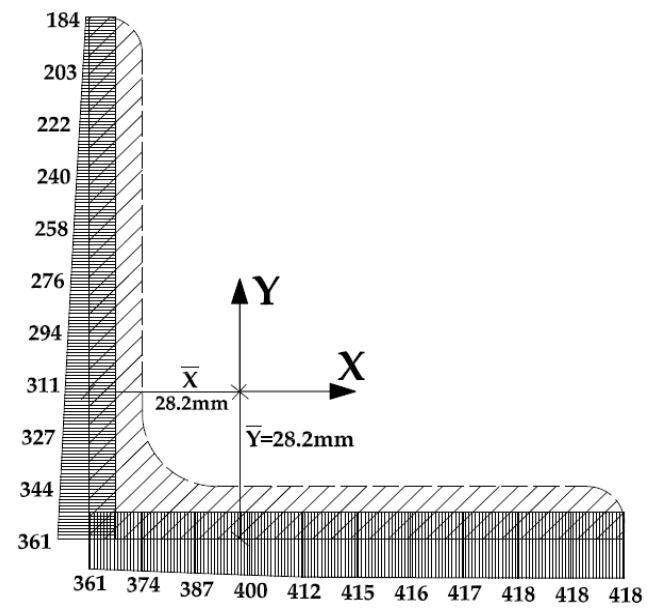

(a) Equal angle $100 \times 100 \times 10$

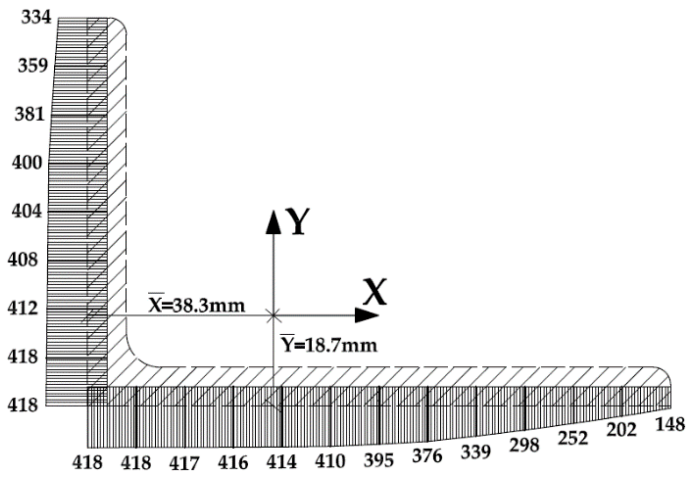

(b) Unequal angle $120 \times 80 \times 10$

Figure 14. Ultimate stress distributions for angles with no deformation in the y-axis direction

\section{- End Deformations with No Deformations in $x$ - and $y$-Axis Directions}

The best stress distributions are obtained when no deformations are allowed in the direction perpendicular to the load axis or perpendicular or parallel to the direction of the unconnected angle leg ( $\mathrm{x}$ - and $\mathrm{y}$-axes), as shown in Figure 15. From this figure it is clear that although deformations are prevented at the end of the steel element, there are deformations within the steel element length, and this results from the presence of a distance between the influence of the load and the center of the single-angle. Also, there is no deformation in the other direction due to the lack of an effective load in the unconnected angle leg. The stress is regularly distributed along the connected leg, remaining almost constant over the entire length. As for the unconnected angle leg, only tensile stress, and no compression stress is measured, as shown in Figure 16. As a result of the presence of a bending moment in the disconnected angle leg direction, the non-uniform distribution of tensile stress occurs along the disconnected angle leg. This deformation is the closest to the system in which the design code is built on.

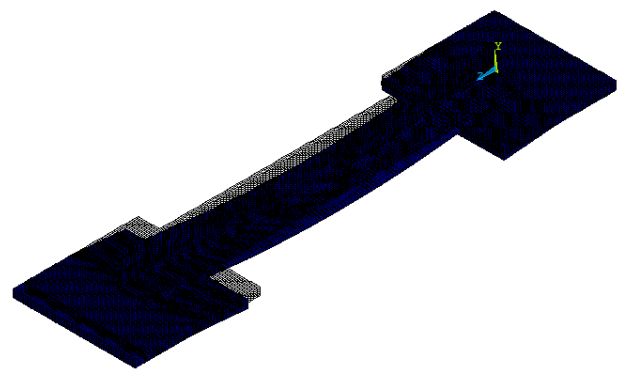

(a) Three-dimensional view

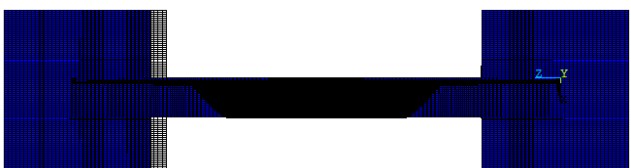

(b) Perpendicular to the unconnected leg

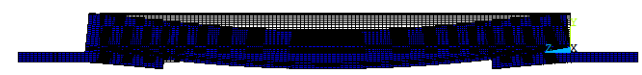

(c) Parallel to the unconnected leg

Figure 15. Deformation shape of steel angle member with no deformations in the $x$ - and $y$-axis directions

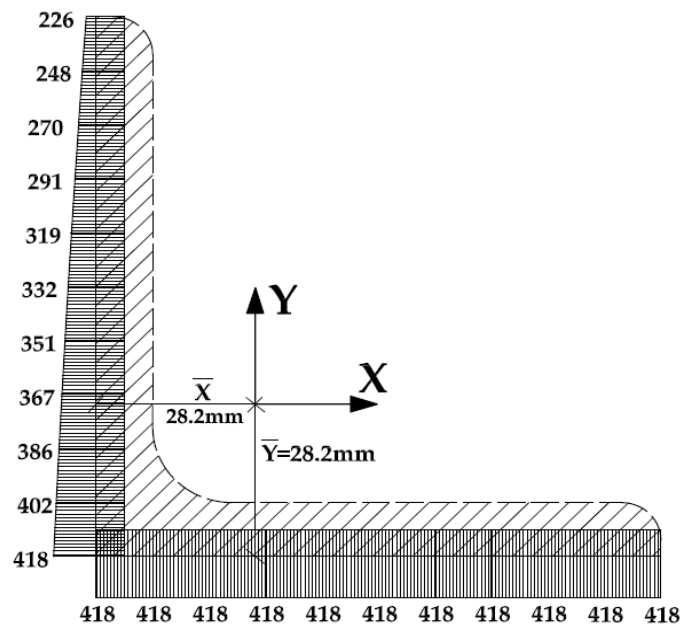

(a) Equal angle $100 \times 100 \times 10$

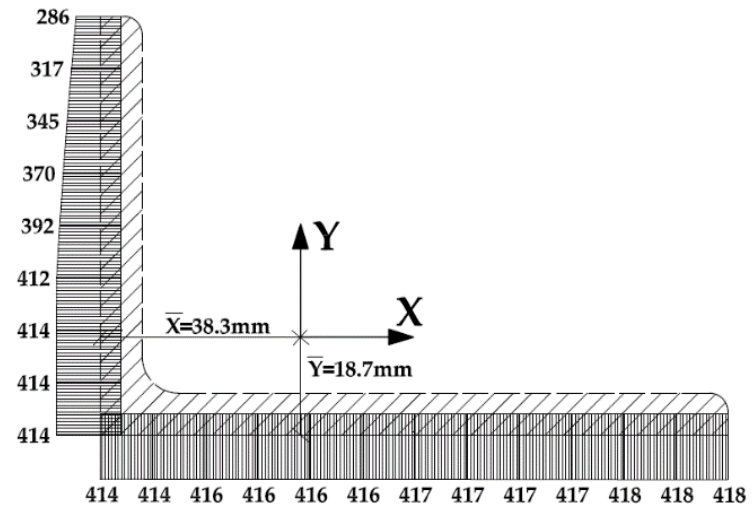

(b) Unequal angle $120 \times 80 \times 10$

Figure 16. Ultimate stress distributions for angles with no deformations in the $x$ - and $y$-axis directions 


\section{- Comparing Different End Deformations}

Table 4 shows the ultimate axial load capacities for the different end deformations of the steel element. The worst loading case occurs with free deformations in all directions at the end of the steel element. Constraining these deformations increases the ultimate load capacity along the direction of the controlled axis. For the equal single angle with no deformation in the $\mathrm{x}$-axis direction, which is perpendicular to the unconnected angle leg, the average load capacity increases by a factor of up to 1.25 compared with that of the angle with free deformations. If no deformation is allowed in the y-axis direction, which is parallel to the unconnected angle leg, the average load capacity increases by a factor of up to 1.81. If no deformations are allowed in either the $\mathrm{x}$ - or $\mathrm{y}$-axis direction, the average increment factor is 1.96, as shown in Figure (17-a). For the unequal single angles, the average increment ratios are 1.23, 2.05, and 2.21 for no deformations in the $\mathrm{x}$-axis, $\mathrm{y}$-axis, and $\mathrm{x}$ - and $\mathrm{y}$-axis, respectively, as shown in Figure (17-b).

Table 4. Comparison of ultimate load capacities with different end deformations.

\begin{tabular}{|c|c|c|c|c|c|c|c|c|}
\hline \multirow{2}{*}{$\begin{array}{c}\text { Angle } \\
\text { specimen }\end{array}$} & \multicolumn{2}{|c|}{$\begin{array}{l}\text { Free deformations in } x-, y-, \\
\text { and } z \text {-axes }\end{array}$} & \multicolumn{2}{|c|}{ No deformation in $x$-axis } & \multicolumn{2}{|c|}{ No deformation in $y$-axis } & \multicolumn{2}{|c|}{$\begin{array}{l}\text { No deformations in } x \text { - and } y \text { - } \\
\text { axis }\end{array}$} \\
\hline & $\begin{array}{l}\text { Ultimate } \\
\text { load }(k N)\end{array}$ & $\boldsymbol{P}_{\text {free }} / \boldsymbol{P}_{\text {free }}$ & $\begin{array}{c}\text { Ultimate } \\
\operatorname{load}(\mathbf{k N})\end{array}$ & $\begin{array}{c}\boldsymbol{P}_{\text {control } x} / \\
\boldsymbol{P}_{\text {free }}\end{array}$ & $\begin{array}{c}\text { Ultimate } \\
\text { load }(k N)\end{array}$ & $\begin{array}{c}\boldsymbol{P}_{\text {control } y} / \\
\boldsymbol{P}_{\text {free }}\end{array}$ & $\begin{array}{l}\text { Ultimate } \\
\text { load }(k N)\end{array}$ & $\boldsymbol{P}_{\text {cntrol } x \& y} / \boldsymbol{P}_{\text {free }}$ \\
\hline $50 \times 50 \times 5$ & 92.38 & 1.00 & 117.53 & 1.27 & 167.9 & 1.82 & 179.14 & 1.94 \\
\hline $75 \times 75 \times 7$ & 193.43 & 1.00 & 240.87 & 1.25 & 349.08 & 1.80 & 378.64 & 1.96 \\
\hline $100 \times 100 \times 10$ & 356.92 & 1.00 & 436.23 & 1.22 & 648.47 & 1.82 & 709 & 1.99 \\
\hline $60 \times 40 \times 5$ & 84.95 & 1.00 & 104.23 & 1.23 & 172.28 & 2.03 & 186.25 & 2.19 \\
\hline $90 \times 60 \times 6$ & 153.22 & 1.00 & 189.16 & 1.23 & 315.26 & 2.06 & 342.68 & 2.24 \\
\hline $120 \times 80 \times 10$ & 337.09 & 1.00 & 409.27 & 1.21 & 696.83 & 2.07 & 743.02 & 2.20 \\
\hline
\end{tabular}

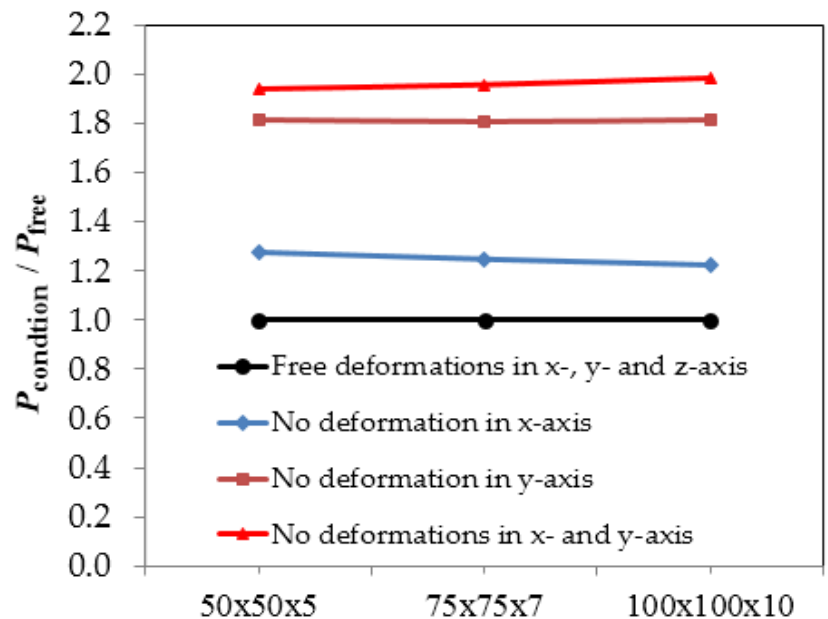

Angle dimensions

(a) Equal angles

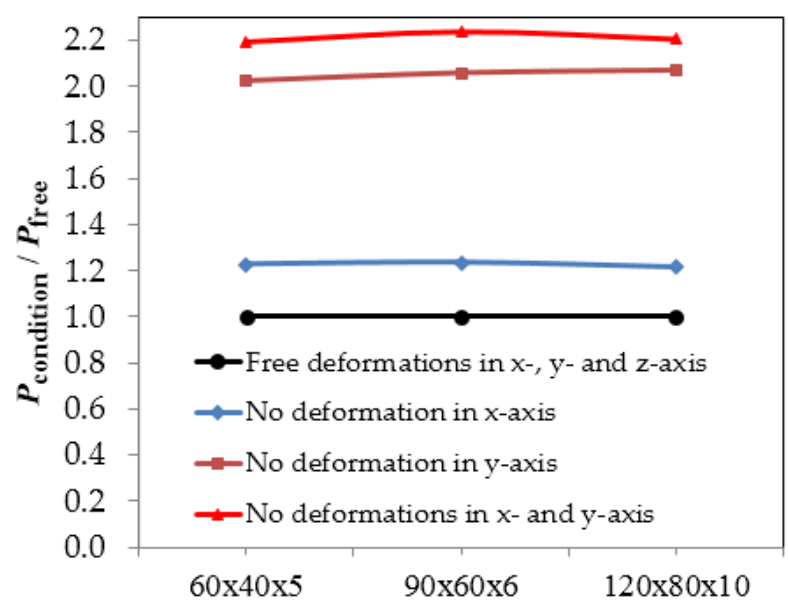

Angle dimensions

(b) Unequal angles

Figure 17. Comparison of the ratio of ultimate load capacity with different end deformations

\section{Comparison of FE Results with Current Design Code}

When using design codes, the calculated value must be multiplied by an appropriate safety coefficient to avoid problems with the structure. Therefore, the load calculated from the design codes should be less than or equal to the load which is actually supported by the element. The design equation proposed by ANSI/AISC-360 [23] is compared with the FE results to verify the accuracy, as summarized by the ratios between ultimate axial load capacities predicted by the design code [23] and FE results given in Table 5. Figure 18 also shows a graphical comparison of the analytical and FE results. For equal single angles, the mean axial load capacity ratios $P_{\text {Num }} / P_{\text {code }}$ calculated from the current design code [23] are $0.68,0.84,1.23$, and 1.33 for end deformations of free deformations, no deformation in the $\mathrm{x}$-axis direction, no deformation in the y-axis direction, and no deformation in the $\mathrm{x}$ - or $\mathrm{y}$-axis direction, respectively. Similarly, the ratios for unequal single angles are calculated from the current design code [23] as $0.61,0.74,1.25$, and 1.34, respectively, for the same end deformations. These ratios illustrate that the design code [23] can be adopted for end deformations with no deformation in the $\mathrm{y}$-axis and no deformation in the $\mathrm{x}$ - or $\mathrm{y}$-axis direction as an exceptional match case, but it does not agree with the end deformations of free deformations and no deformations in the $\mathrm{x}$-axis 
direction for equal or unequal angles, which is unsafe. Additionally, these ratios illustrate that in terms of durability, an equal single angle with no deformations in the $\mathrm{x}$ - or $\mathrm{y}$-axis direction is the most ideal, followed in order by no deformation in the $\mathrm{y}$-axis direction, no deformation in the $\mathrm{x}$-axis direction, and free deformations in the $\mathrm{x}-, \mathrm{y}-$, and $\mathrm{z}-$ axis directions.

Table 5. Comparison of ultimate loads between current design code (ANSI/AISC-360) [23] and FE results

\begin{tabular}{|c|c|c|c|c|c|c|c|c|c|}
\hline \multirow{2}{*}{$\begin{array}{c}\text { Angle } \\
\text { specimen }\end{array}$} & \multirow{2}{*}{$\begin{array}{c}\text { ANSI / } \\
\text { AISC } \\
\text { code } \\
(\mathbf{k N})\end{array}$} & \multicolumn{2}{|c|}{$\begin{array}{c}\text { Free deformations in } x \text {-, } \\
\qquad y \text {-, and } z \text {-axes }\end{array}$} & \multicolumn{2}{|c|}{ No deformation in $x$-axis } & \multicolumn{2}{|c|}{$\begin{array}{l}\text { No deformation in } y \text { - } \\
\text { axis }\end{array}$} & \multicolumn{2}{|c|}{$\begin{array}{l}\text { No deformations in } x \text { - and } \\
y \text {-axis }\end{array}$} \\
\hline & & $\begin{array}{l}\text { Ultimate } \\
\text { load (kN) }\end{array}$ & $\begin{array}{l}P_{\text {Num }} / \\
P_{\text {code }}\end{array}$ & $\begin{array}{l}\text { Ultimate } \\
\text { load }(k N)\end{array}$ & $\begin{array}{c}P_{\text {Num }} / \\
P_{\text {code }}\end{array}$ & $\begin{array}{l}\text { Ultimate } \\
\text { load (kN) }\end{array}$ & $\begin{array}{c}P_{\text {Num }} / \\
P_{\text {code }}\end{array}$ & $\begin{array}{c}\text { Ultimate load } \\
(\mathrm{kN})\end{array}$ & $\begin{array}{l}P_{\text {Num }} / \\
P_{\text {code }}\end{array}$ \\
\hline $50 \times 50 \times 5$ & 139.95 & 92.38 & 0.66 & 117.53 & 0.84 & 167.90 & 1.20 & 179.14 & 1.28 \\
\hline $75 \times 75 \times 7$ & 283.54 & 193.43 & 0.68 & 240.87 & 0.85 & 349.08 & 1.23 & 378.64 & 1.34 \\
\hline $100 \times 100 \times 10$ & 517.05 & 356.92 & 0.69 & 436.23 & 0.84 & 648.47 & 1.25 & 709.00 & 1.37 \\
\hline $60 \times 40 \times 5$ & 142.88 & 84.95 & 0.59 & 104.23 & 0.73 & 172.28 & 1.21 & 186.25 & 1.30 \\
\hline $90 \times 60 \times 6$ & 253.23 & 153.22 & 0.61 & 189.16 & 0.75 & 315.26 & 1.24 & 342.68 & 1.35 \\
\hline $120 \times 80 \times 10$ & 540.40 & 337.09 & 0.62 & 409.27 & 0.76 & 696.83 & 1.29 & 743.02 & 1.37 \\
\hline
\end{tabular}

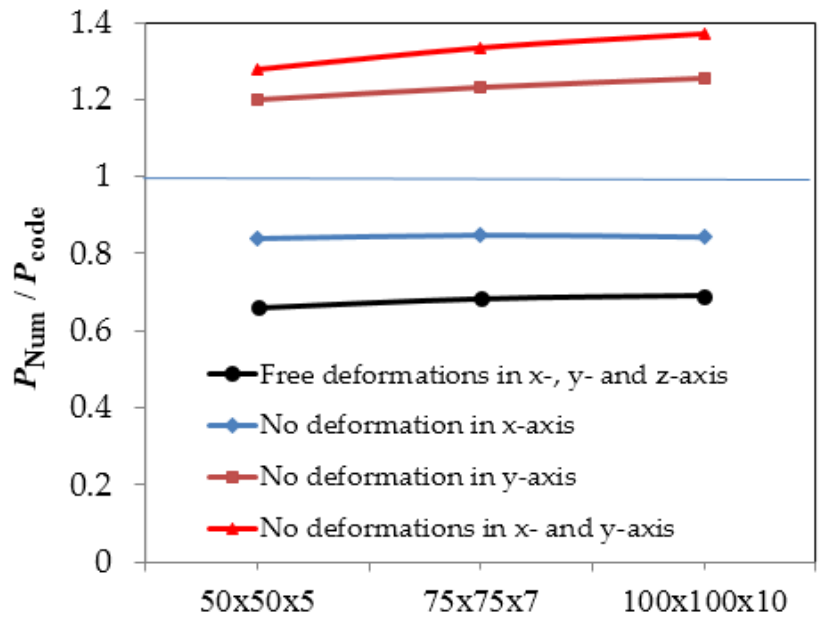

Angle dimensions

(a) Equal angles

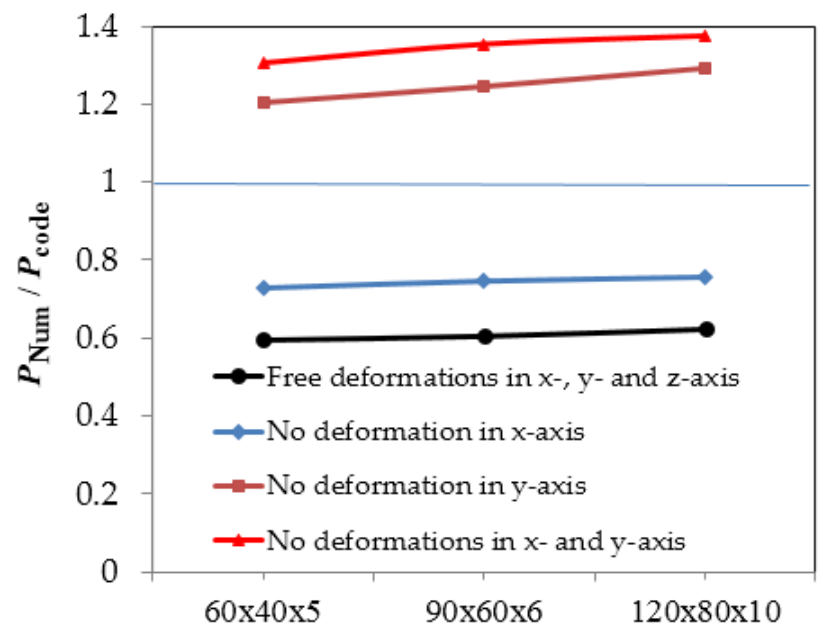

Angle dimensions

(b) Unequal angles

Figure 18. Comparison of ultimate load capacity obtained from FE results and the current design code (ANSI/AISC-360) [23]

\section{Conclusion}

In this study, the deformations occurring at the end of the steel element with a cross-section of an equal or unequal single-angle is proved to affect the shape of the stress distribution as well as the maximum load capacity of the steel element. To this end, the FE modeling is used on a number of 50 samples with equal and unequal single angles with different end deformations. Various parameters are fed into the ANSYS software, including angle dimensions, crosssectional area, equal and unequal angle dimensions, steel element length, and end deformations. Two samples are used to verify the accuracy of the used modeling in predicting the maximum capacity of the steel element. This verification demonstrates high accuracy in predicting the maximum load capacity using numerical analysis. Forty-eight samples are used to study the stresses distribution and also to compare the maximum load capacity resulting from the FE modeling with the current design codes. The results demonstrate that there is an appearance of a compression zone in the unconnected angle leg that is affected by the end deformations, and consequently, the ultimate load capacity is affected. Interestingly, this phenomenon is not considered before in the existing codes. Also, the current design code (ANSI/AISC-360) is found to be able to calculate the ultimate load in the case of no deformation in the y-axis direction and no deformations in the $\mathrm{x}$ - and $\mathrm{y}$-axis directions. However, the code does not agree with the end deformations of free deformations and no deformation in the $\mathrm{x}$-axis direction for either equal or unequal angles, which is unsafe. For the ultimate axial load capacities of equal and unequal single angle members, the mean ratios calculated form the ANSI/AISC-360 of PNum/Pcode are 0.64, 0.79, 1.24, and 1.34 for free deformations, no deformations in the $\mathrm{x}$-axis, no deformations in the $\mathrm{y}$-axis, and no deformations in the $\mathrm{x}$ - and $\mathrm{y}$-axis, respectively. Finally, the length of the steel element with a single-angle cross-section under a tension force shows no effect on the stress distribution or ultimate load capacity, which is consistent with existing design codes. Further research could focus on steel members 
with a single angle cross-section under cyclic loading, which is received little attention on the literature. All these new research results direct the existing codes to complete the gaps of design.

\section{Funding and Acknowledgments}

The deanship of Scientific Research, Majmaah University, deserves special thanks for his generous support in the accomplishment of this task under Project Number No. 1439-46.

\section{Conflicts of Interest}

The authors declare no conflict of interest.

\section{References}

[1] Može, Primož, Luis-Guy Cajot, Franc Sinur, Klemen Rejec, and Darko Beg. "Residual Stress Distribution of Large Steel Equal Leg Angles.” Engineering Structures 71 (July 2014): 35-47. doi:10.1016/j.engstruct.2014.03.040.

[2] Kirkham W.J., and Miller T.H. "Examination of AISC LRFD Shear Lag Design Provisions." AISC Engineering Journal 37, no. 3 (2000):83-98.

[3] Teh, Lip H., and Benoit P. Gilbert. "Net Section Tension Capacity of Cold-Reduced Sheet Steel Angle Braces Bolted at One Leg." Journal of Structural Engineering 139, no. 3 (March 2013): 328-337. doi:10.1061/(asce)st.1943-541x.0000675.

[4] Charalampakis, A.E. "Full Plastic Capacity of Equal Angle Sections under Biaxial Bending and Normal Force." Engineering Structures 33, no. 6 (June 2011): 2085-2090. doi:10.1016/j.engstruct.2011.02.044.

[5] Kuralkar S.D., and Oswal S.S. "Biaxial Bending of Steel Angle Section.” International Journal of Engineering Research 5, no. 1 (2016):232-234.

[6] Trahair N.S. "Moment Capacities of Steel Angle Sections." Journal of Structural Engineering 128, no. 11 (2002):1387-1393. doi:10.1061/(ASCE)0733-9445(2002)128:11(1387).

[7] Zhu,, H.T., Michael C.H. Yam, Angus C.C. Lam, and V.P. Iu. "The Shear Lag Effects on Welded Steel Single Angle Tension Members.” Journal of Constructional Steel Research 65, no. 5 (May 2009): 1171-1186. doi:10.1016/j.jcsr.2008.10.004.

[8] Kitipornchai, S., and H.W. Lee. "Inelastic Buckling of Single-Angle, Tee and Double-Angle Struts." Journal of Constructional Steel Research 6, no. 1 (January 1986): 3-20. doi:10.1016/0143-974x(86)90018-0.

[9] Shi, Gang, Wen-jing Zhou, Yu Bai, and Zhao Liu. "Local Buckling of Steel Equal Angle Members with Normal and High Strengths.” International Journal of Steel Structures 14, no. 3 (September 2014): 447-455. doi:10.1007/s13296-014-3002-0.

[10] Epstein, H.I., and R. Chamarajanagar. "Finite Element Studies for Correlation with Block Shear Tests." Computers \& Structures 61, no. 5 (December 1996): 967-974. doi:10.1016/0045-7949(96)00083-1..

[11] Barth, K.E., J.G. Orbison, and R. Nukala. "Behavior of Steel Tension Members Subjected to Uniaxial Loading." Journal of Constructional Steel Research 58, no. 5-8 (January 2002): 1103-1120. doi:10.1016/s0143-974x(01)00082-7.

[12] Makesh A.P., and Arivalagan S. "Experimental and Analytical Study on Behaviour of Cold Formed Steel Using Angle Section under Tension Members." International Journal of Engineering Technologies and Management Research 5, no. 1 (2018):2028. doi: 10.5281/zenodo.1157620.

[13] Epstein H.I., and DAiuto C.L."Using Moment and Axial Interaction Equations to Account for Moment and Shear Lag Effects in Tension Members.” Engineering Journal 39, no. 2 (2002):91-99.

[14] Liu Y., and Chantel S. "Experimental Study of Steel Single Unequal-Leg Angles under Eccentric Compression." Journal of Constructional Steel Research 67, no. 6 (2011):919-28. doi:10.1016/j.jcsr.2011.02.005.

[15] Torabipour, Ahmadreza, and M. R. Shiravand. "Development Behavior for Post-Tensioned Self-Centering Steel Connection under Cyclic Loading." Civil Engineering Journal 3, no. 3 (March 30, 2017): 152-159. doi:10.28991/cej-2017-00000081.

[16] Kulak G.L., and Wu E.Y. "Shear Lag in Bolted Angle Tension Members." Journal of Structural Engineering 123, no.9 (1997):1144-1152. doi: 10.1061/(ASCE)0733-9445(1997)123:9(1144).

[17] Trahair N.S. "Biaxial Bending of Steel Angle Section Beams.” Journal of Structural Engineering, 130, no. 4 (2004):554-561. doi: 10.1061/(ASCE)0733-9445(2004)130:4(554).

[18] Priya C.B., Keerthana M., Verma M., and Banjara N.K. "Design of Steel Channel Tension Members-Proposal to IS 800:2007.” Journal of Structural Engineering 38, no. 2 (2011):122-130. 
[19] Gupta M., and Gupta L.M. "Evaluation of Stress Distribution in Bolted Steel Angles under Tension.” Electronic Journal of Structural Engineering, 4, (2004):17-25.

[20] Hussain, A., Yao-Peng Liu, and Siu-Lai Chan. "Finite Element Modeling and Design of Single Angle Member under Bi-Axial Bending." Structures 16 (November 2018): 373-389. doi:10.1016/j.istruc.2018.11.001.

[21] Sayed, Ahmed M., and Hesham M. Diab. "Modeling of the Axial Load Capacity of RC Columns Strengthened with Steel Jacketing Under Preloading Based on FE Simulation.” Modelling and Simulation in Engineering 2019 (March 4, 2019): 1-8. doi:10.1155/2019/8653247.

[22] Sayed, Ahmed M. "Numerical Analysis of the Perforated Steel Sheets under Uni-Axial Tensile Force." Metals 9, no. 6 (May 31, 2019): 632. doi:10.3390/met9060632.

[23] ANSI/AISC-360. "Specification for Structural Steel Buildings.” ANSI/AISC 360-16, Chicago (2016).

[24] British Standards Institution (BSI). BS EN 1993-1-1: Eurocode 3: "Design of Steel Structures Part 1-1: General Rules and Rules for Building.” London: BSI. (2005).

[25] Standards Australia (SA) “Steel Structures.” AS 4100-1998, Sydney, Australia (1998).

[26] ANSYS User's Manual, Version 15 “Swanson Analysis Systems.” Inc., Cannonsburg, PA, USA (2015). 